\title{
Original article \\ Effect of different concentrations of coconut water on ram sperm kinematic parameters
}

\author{
Ilas Vlad, Pall Emoke, Tripon Mirela, Sinteonean Lavinia, Cerbu Constantin* and GrozaIoan Stefan \\ Department of Clinical Sciences, Department of Clinical Reproduction, University of Agricultural Sciences and \\ Veterinary Medicine, Manastur Street, 3-5, Cluj-Napoca, Romania \\ *Department of Clinical Sciences, Infectious-Diseases, University of Agricultural Sciences and \\ Veterinary Medicine, Str. Manastur No. 3-5, Cluj-Napoca, Romania
}

Received September 1, 2018: Revised October 16, 2018: Accepted October 19, 2018: Published online December 30, 2018

\begin{abstract}
Romania's shepherding heritage is widely recognized. Sheep, shepherding and transhumance are ubiquitous in Romania, as fundamental for Romanian identity and economy. An overwhelming percentage of the total sheep population consists of, or is linked to the very old, hardy and resistant Turcana breed. Our aim is to improve growth rate, production and prolificity by maximizing the impact of high genetic value rams on local populations. The objective of our study was to evaluate the effect of two different concentrations of coconut water (Cocos nucifera L.) on the kinematic parameters of ram semen. Six ejaculates were collected from Turcana rams by electro-ejaculation. After microscopic analysis, two aliquots per ejaculate were diluted with Tris based extender (Tris, Citric acid, Fructose, D-glucose), supplemented with 10\% and 20\% commercial coconut water. The control aliquots were diluted with unsupplemented Tris extender. After equilibration, the kinematic parameters of semen were evaluated every $48 \mathrm{~h}$. The ram sperm parameters were significantly higher $(p<0.05)$ in the $10 \%$ and $20 \%$ coconut supplemented groups compared with control group. Based on CASA analysis sperm, motility, membrane integrity and acrosomal intactness were best preserved using the $20 \%$ coconut water supplemented extender. This study evaluated the potential of natural coconut water based extenders as an alternative to well established, commercial sperm mediums. Coconut water enriched media offer a safe and costeffective improvement to classic/commercial extenders for ram semen preservation.
\end{abstract}

Key words: Ram, CASA, semen, coconut water, Cocos nucifera $\mathrm{L}$.

\section{Introduction}

Official data suggested that up to $90 \%$ of the estimated 9 million Romanian sheep population consists of, or is linked to the hardy and resistant Turcana breed (Vasile et al., 2011; Gavojdian et al., 2013; Ministry of Agriculture and Rural Development-National Agency for Animal Husbandry, 2013; National Institute of Statistics, 2016). Much of the sheepherding business total income is represented by the capitalization on lamb trading. Up to $66 \%$ of the total returns are represented by this activity (Gavojdian et al., 2013).

Considering the economic element, improving prolificity and average gain by maximizing the impact of high value rams is of utmost importance. Genetic value aside, ram fertility is a major factor regarding prolificacy in sheep. Improving semen preservation, particularly the post storage kinematic parameters is essential and could also improve the outcome and success rate of peri cervical artificial insemination (AI), a more accessible approach than the laparoscopic, transcervical, intrauterine deposition of semen. Being

\footnotetext{
Author for correspondence: Mr. Ilas Vlad

Department of Clinical Sciences, Department of Clinical Reproduction, University of Agricultural Sciences and Veterinary Medicine, Manastur Street, 3-5, Cluj-Napoca, Romania

E-mail: vlad.ilas@usamvcluj.ro

Tel.: +40-264596384/163
}

Copyright @ 2018 Ukaaz Publications. All rights reserved.

Email: ukaaz@yahoo.com; Website: www.ukaazpublications.com able to frugally preserve high quality semen could be a way towards economic success.

Coconut water-based extenders can provide a buffering, non-toxic, low cost, practical, and effective alternative to proven semen extenders (Cardoso et al., 2005; Silva et al., 2012). Coconut water is well known for its versatility, being used in a wide array of fields. Surprisingly, considerable confusion around the terms 'coconut water' and 'coconut milk' has led to their interchangeable use, the cause being the interweaving, country specific definitions regarding the same or similar products (Seow et al., 1997).

The Standards Task Force of the APCC consider the term 'coconut water' to strictly stand for the natural aqueous liquid endosperm of the drupe of $C$. nucifera L., while the terms 'coconut milk' or 'coconut cream' should refer to the aqueous products, essentially fibre free, extracted from solid coconut endosperm, but which optionally may include traces of coconut water. In short, the term coconut water is used for the aqueous part of the endosperm, whereas coconut milk for the liquid products obtained from solid endosperm (Standards Task Force Asian and Pacific Coconut Community (APCC), 1994; Yong et al., 2009). Necessary cell conservation elements, such as salts, proteins, sugars, vitamins, neutral fats, cell division inducers and electrolytes are richly found in coconut water (Blume and Marques Jr, 1994). Intense metabolism is a cause of an increase in reactive oxygen species levels (free radicals), as a result of oxidative metabolism. Coconut water 
micronutrients such as inorganic ions and vitamins could play an important antioxidant role to prevent free radical cell oxidative damage (Evans and Halliwell, 2001). By electron donation, micronutrients have a vast contribution preventing this kind of damage, actively help quenching free radicals or indirectly acting as part of enzymes that are conditioned by catalytic metal ions for their biological activity. The removal of oxidizing species is catalysed by such metalloenzymes as glutathione peroxidase (selenium dependent) or superoxide dismutase (zinc, copper, as cofactors) (Shenkin, 2006). Various amounts of sugars, sugar alcohols, lipids, amino acids, nitrogenous compounds, organic acids and enzymes are contained within coconut water (Tulecke et al., 1961; Arditti, 1994; Santoso et al., 1996; USDA, 2011). The ability to protect against cold shock relies on the strong antioxidant capacity, thus protecting spermatozoa from oxidative damage during low temperature processes (Seeram et al., 2005; Tezcan et al., 2009). Egg yolk provides much needed sperm membrane protection, restoring phospholipids lost due to cold exposure and thermal shock (Hammerstedt et al., 1990).

The objective of our study was to evaluate the effect of two different coconut water ( $C$. nucifera) concentrations on the kinematic parameters of ram semen during liquid storage.

\section{Materials and Methods}

Semen from a total of six sexually mature (22-29 months), Turcana rams was used. The individuals belonged to a private farmer, located in Hida, Zalãu, Romania. During the extent of the study, animal manipulations were performed within strict accordance with the Romanian animal protection regulation, which conforms to European Union Directive 2010/64/EU(EU, 2010). The animals were isolated from the rest of the flock before the start of the study and housed in an outdoor paddock. Water and high-quality feed were provided ad libitum. Feed was withheld the night before $(12 \mathrm{~h})$ induction of anaesthesia. General anaesthesia was induced with a single dose of xylazine $(0,1 \mathrm{mg} / \mathrm{kg}$, intramuscularly $)+$ ketamine $(4 \mathrm{mg} / \mathrm{kg}$, intravenously) (Narcoxyl 2\%; Intervet International, The Netherlands and Ketaminol 10; MSD Animal Health, The Netherlands). The animals were kept in lateral recumbency and the preputial area was groomed, washed with physiological saline serum and dried with a clean cloth. Semen was collected using an electro ejaculator. Electric stimulation was applied using a $20 \mathrm{~cm}$ by $3 \mathrm{~cm}$, 3 -electrode probe. Each stimulus lasted for $5 \mathrm{sec}$, with intermittent breaks of $5 \mathrm{sec}$ during 5 min cycles. Semen was collected in preheated glass tubes, pooled and evaluated. Semen samples (control) were diluted $1: 50$ at $37^{\circ} \mathrm{C}$ with a tris-glucose-citric acid extender supplemented with egg yolk $(10 \%, \mathrm{v} / \mathrm{v})$ and stored at $4^{\circ} \mathrm{C}$. Coconut water Tris supplemented extender (10\%, v/v; 20\% v/v) samples were diluted using the same protocol. Sperm kinetic parameters and vitality were reassessed using CASA system (Microptic, Barcelona, Spain) at $48 \mathrm{~h}$.

\section{Results and Discussion}

The study was performed using a split-sample design. Data were analysed using GraphPad Prism 6 software (Manual Graph Pad Prism 5.0, GraphPad Software). Results were presented as Mean \pm SEM. A value of $p<0.05$ was considered statistically significant. After macroscopic evaluation and concentration assessment, the samples were diluted using three different extenders: Tris based extender (TE) - control group and experimental groups TEC10 and TEC20 (Tris based extender supplemented with $10 \%$ and $20 \%$ of coconut water). Sperm vitality and kinematic parameters (curvilinear velocity, straight line velocity, average path velocity, linearity index, amplitude of lateral head displacement, straightness index, oscillation index, amplitude lateral head, beat frequency) were evaluated in each sample using CASA system. The average of progressive motility in control group was $69.34 \% \pm 1.07 ; 73.64 \%$ \pm 3.40 in TEC 10 group and $83.85 \% \pm 1.35$, respectively (Figure 1 ).



Figure 1: Progressive motility in ram spermatozoa diluted in three different extenders at $48 \mathrm{~h}$.

The average of curvilinear velocity in control group was $60.34 \% \pm$ $1.02,71.51 \% \pm 2.08$ in $10 \%$ coconut water supplemented group and $83.68 \% \pm 1.77$ in TEC20, respectively (Figure 2).

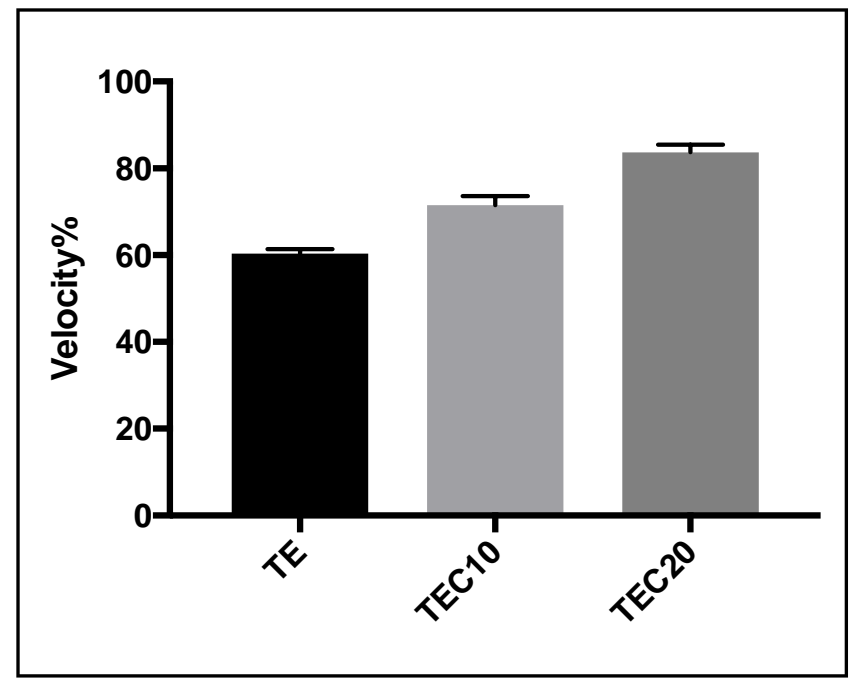

Figure 2: The average of curvilinear velocity in ram spermatozoa diluted in three different extenders.

The rest of evaluated kinematic parameters as well as straight-line velocity (VSL), average path velocity (VAP), the straightness index, the linearity index, the amplitude of lateral head displacement, beatcross frequency values show significantly improved results in $10 \%$ and $20 \%$ coconut water supplemented groups (Table1). 
Table 1: Ram semen kinematic parameters

\begin{tabular}{|c|c|c|c|c|c|c|c|c|c|c|c|c|c|}
\hline \multirow[t]{2}{*}{ Avg.valuesofspeed } & \multicolumn{3}{|c|}{ Average } & \multicolumn{3}{|c|}{ Slow } & \multicolumn{3}{|c|}{ Medium } & \multicolumn{3}{|c|}{ Rapid } & \multirow[t]{2}{*}{ Units } \\
\hline & TE & TE10\% & TE20\% & $\mathbf{T E}$ & TE10\% & TE20\% & TE & TE10\% & TE20\% & TE & TE10\% & TE20\% & \\
\hline Curvespeed-VCL & 87.32 & $\begin{array}{l}96.51 \\
43.35 \\
74.57\end{array}$ & 107.48 & 18.83 & 18.46 & 19.82 & 102.64 & 106.96 & 121.78 & 104.08 & 115.25 & 111.14 & $\mathrm{~mm} / \mathrm{s}$ \\
\hline Linearspeed-VSL & 29.63 & 43.35 & 33.02 & 6.41 & 4.67 & 4.23 & 29.96 & 35.95 & 32.88 & 64.22 & 81.78 & 65.86 & $\mathrm{~mm} / \mathrm{s}$ \\
\hline Avg.value-VAP & 53.28 & 74.57 & 65.61 & 11.18 & 9.52 & 9.80 & 60.94 & 83.12 & 73.68 & 74.02 & 90.55 & 74.70 & $\mathrm{~mm} / \mathrm{s}$ \\
\hline Linearityindex-LIN & 35.24 & 42.51 & 30.46 & 37.74 & 26.99 & 21.96 & 30.04 & 33.75 & 27.39 & 62.15 & 71.34 & 60.01 & $\%$ \\
\hline Straightnessindex-STR & 55.71 & 56.88 & 49.74 & 57.63 & 49.01 & 40.66 & 49.98 & 44.41 & 45.42 & 86.73 & 90.12 & 88.08 & $\%$ \\
\hline Oscillationindex-WOB & 61.78 & 74.72 & 59.77 & 62.35 & 53.28 & 50.34 & 59.99 & 77.96 & 60.10 & 71.52 & 79.01 & 68.03 & $\%$ \\
\hline
\end{tabular}

\begin{tabular}{|c|c|c|c|c|c|c|c|c|c|c|}
\hline \multirow[t]{2}{*}{ Avg.valuesofotherparameters } & \multicolumn{3}{|c|}{ Average } & \multicolumn{3}{|c|}{ Medium } & \multicolumn{3}{|c|}{ Rapid progressive } & \multirow[t]{2}{*}{ Units } \\
\hline & $\mathbf{T E}$ & TE10\% & TE20\% & $\mathbf{T E}$ & TE10\% & TE20\% & $\mathbf{T E}$ & TE10\% & TE20\% & \\
\hline Amplitudelateralhead-ALH & 3.68 & 3.35 & 4.40 & 4.29 & 3.63 & 4.95 & 3.95 & 3.89 & 4.28 & $\mathrm{~mm}$ \\
\hline Beatfrequency-BCF & 7.25 & 5.83 & 7.78 & 8.04 & 5.85 & 8.42 & 8.56 & 7.70 & 9.52 & $\mathrm{~Hz}$ \\
\hline
\end{tabular}

The sperm vitality in control groups were $70.18 \pm 1.51 \%$, in TEC10 group $76.99 \pm 0.69 \%$ and $85.85 \pm 3.71 \%$ in TEC20, respectively (Figure.3).

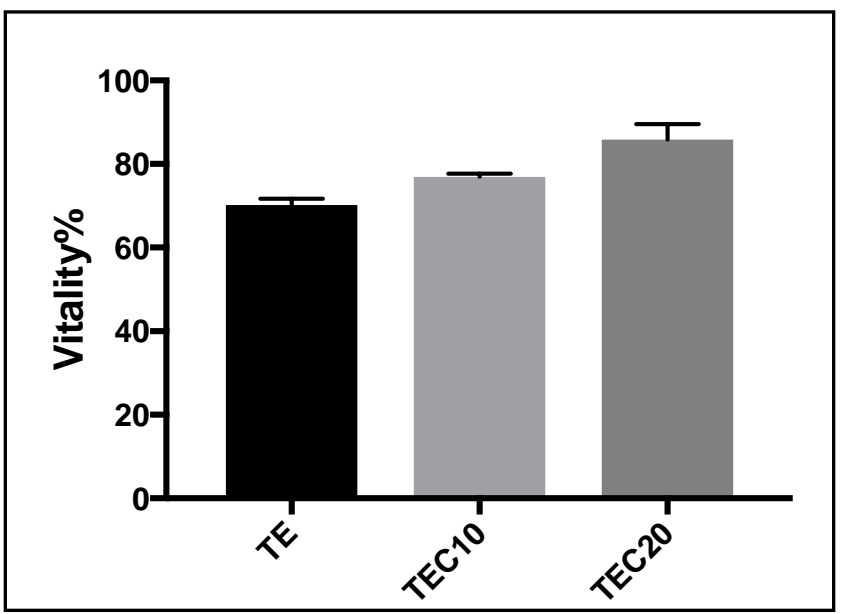

Figure 3: The average of vitality distribution in ram spermatozoa diluted in three different extenders.

Regardless of the used extender, semen endpoints were reduced after low temperature exposure. Cell viability loss and a decrease in motility as a cause of exposure to refrigeration temperatures, extenders and during the return to isosmotic conditions must be taken into account during liquid storage.

Results for the control samples are similar to those previously reported by Câmara et al. (2011) and Rajashri et al. (2017) and also comparable to the results obtained by a standard estimation method using a phase contrast microscope (Gündoðan, 2009).

The addition of $10 \%$ coconut water had a positive effect on sperm liquid storage quality and outperformed the unsupplemented media. The percentage of viable and motile spermatozoa improved along with the increase in coconut water concentration in the tris-based extender. Results shown that enhancing the used extender with $20 \%$ coconut water provided the best results regarding sperm characteristics after cold storage, being an improvement over the unsupplemented media and the $10 \%$ coconut water extender $(p<0.05)$.
In order of achieving satisfactory liquid storage sperm vitality and kinematic parameters we recommend the addition of $20 \%$ coconut water. The applied electroejaculation method, provided good quality ejaculates from all individuals, with no negative impact on semen quality with the added benefit of eliminating the need for a training period for the rams, as required for artificial vagina use.

\section{Conclusion}

The results of the present study showed that the addition of coconut water to a TRIS based extender is beneficial to sperm kinematic parameters after liquid storage. The supplementation of the TRIS media with $20 \%$ coconut water constantly provided better results. Increasing the semen liquid storage kinematic parameters is a step towards increasing the success rate of peri cervical insemination, a much simpler and accessible method of artificial insemination. The tested coconut water enhanced tris extender proved effective for the liquid storage of Turcana ram semen improving sperm viability and kinematic parameters during storage.

However, the results presented here are based on in vitro evaluations and further studies must be performed in order to evaluate whether the extenders and cooling conditions tested have any influence on the fertility results after artificial insemination under field conditions.

\section{Conflict of interest}

We declare that we have no conflict of interest.

\section{References}

Arditti, J. (1994). Micropropagation of orchids. Biological Conservation., 68:75-76.

Blume, H. and Marques Jr. A. (1994). Valiação da água de coco no cultivo e criopreservação de embriões murídeos (Evaluation of coconut water for the culture and cryopreservation of murid embryos). A Rev. Bras. Reprod. Anim., pp:97-104.

Câmara, D. R.; Silva, S. V.; Almeida, F. C.; Nunes, J. F. and Guerra, M. M. P. (2011). Effects of antioxidants and duration of pre-freezing equilibration on frozen-thawed ram semen. Theriogenology, 76:342-350. 
Cardoso, R.C.S.; Silva, A. R. and Silva, L. D. M. (2005). Use of the powdered coconut water (ACP-106®) for cryopreservation of canine spermatozoa. Anim. Reprod., 2:257-262.

EU (2010). Council Directive 2010/63/EU of 22 September 2010 on the protection of animals used for scientific purposes. Official Journal of the European Union, 7:23-27.

Evans, P. and Halliwell, B. (2001). Micronutrients: oxidant/antioxidant status. British Journal of Nutrition., 85:S67.

Gavojdian, D.; Sauer, M.; Padeanu, I.; Pacala, N. and Voia, S. O. (2013). Influence of production system, sex and litter size on growth rates in Turcana. Lambs, 46:357-360.

Gündoðan, M., (2009). Short term preservation of ram semen with different extenders. Kafkas Univ. Vet. Fak. Derg., 15:429-435.

Hammerstedt, R. H.; Graham, J. K. and Nolan, J. P. (1990). Cryopreservation of mammalian sperm: What we ask them to survive? Journal of Andrology, 11:73-88

Ministry of Agriculture and Rural Development-National Agency for Anima Husbandry (2013). Controlul oficial al producpiilor la ovine ${ }^{{ }^{i}} \mathrm{i}$ caprine. Bulletin Technic Informative, 1:14-21.

National Institute of Statistics (2016). National Reference Metadata in ESS Standard for Quality Reports Structure.

Rajashri, M.; Reddy, K. R.; Kumari, G. A.; Kumari, N. N. and Srinivas, G. (2017) Evaluation of semen extenders for preservation of Deccani ram semen at $5^{\circ} \mathrm{C}$ for the use of artificial insemination. J. Vet. Sci., 18:259-263.

Santoso, U.; Kubo, K.; Ota, T.; Tadokoro, T. and Maekawa, A. (1996). Nutrient composition of kopyor coconuts. Food Chemistry, 11:27-32.

Seeram, N. P.; Adams, L. S.; Henning, S. M.; Niu, Y.; Zhang, Y.; Nair, M. G. and Heber, D. (2005). In vitro antiproliferative, apoptotic and antioxidant activities of punicalagin, ellagic acid and a total pomegranate tannin extract are enhanced in combination with other polyphenols as found in pomegranate juice. Journal of Nutritional Biochemistry, 16:360-367.
Seow, C. C. and Gwee, C. N. (1997). Coconut milk: Chemistry and technology. International Journal of Food Science and Technology, 32:189201 .

Shenkin, A.(2006). The key role of micronutrients. Clinical Nutrition., 25:1-13.

Silva, M.A.; Peixoto, G. C. X.; Lima, G. L.; Bezerra, J.A. B.; Campos, L. B.; Paiva A. L. C.; Paula, V. V. and Silva, A. R. (2012). Cryopreservation of collared peccaries (Tayassu tajacu) semen usin g a powdered coconut water (ACP-116c) based extender plus various concentrations of egg yolk and glycerol. Theriogenology, 78:605-611.

Standards Task Force Asian and Pacific Coconut Community (APCC), (1994). International Codes and Standard for Aqueous Coconut Products, 2nd draft. Standards Task Force, Asian and Pacific Coconut Community.

Tezcan, F.; Gültekin-Özgüven, M.; Diken, T.; Özçelik, B. and Erim, F. B. (2009). Antioxidant activity and total phenolic, organic acid and sugar content in commercial pomegranate juices. Food Chemistry, 115: 873-877.

Tulecke, W.; Weinstein, L. H.; Rutner, A. and Laurencot, H. J. (1961). The biochemical composition of coconut water (coconut milk) as related to its use in plant tissue culture. Contrib. Boyce Thompson Inst., pp: 21

USDA (2011). National Nutrient Database for Standard Reference. USDA National Nutrient Database for Standard Reference, Release, pp:24.

Vasile, S.; Georgescu, B.; Ioan, P.; Voia, S.; Pascal, C. and Ioan, C. (2011). Morpho-productive characterization of some tzurcana breed populations, white variety, bred in some zones of Transylvania. Water Molecules, 44:370-375.

Yong, J. W. H.; Ge, L.; Ng, Y. F. and Tan, S. N. (2009). The chemical composition and biological properties of coconut (Cocos nucifera L.). Water Molecules, 14:5144-5164. 